column of blood furnished in most part by the spermatic artery, the obliteration of this vessel and the consequent immediate collapse of the veins, from the diminished quantity of blood flowing through them and now derived from the anastomotic branches, must be followed by a certain state and time of inaction, wherein the vessels are enabled to return to their original diameter; while their comparatively empty condition allows them to course up the inguinal canal, and through the internal iliac regions under the ileum, cxecum, or sigmoid flexure of the colon, without being exposed to that pressure from any of these parts, singly or in combination, and which is the general cause of this disease.

The relative effect of a ligature upon the spermatic artery as influencing the special function of the testicle in the secretion of the semen, is very readily explained; whether the organ is deluged with blood, and increased in its general dimensions (hypertrophy), or whether it is partly starved out and gradually diminishing and wasting (atrophy), the same results are to be apprehended in both states-an impairment of the function of secretion, in the one case, from an augmented, and in the other from a diminished flow of blood, the eliminating process being feebly maintained for a variable period. The ultimate results are, however, very different. In one case we have to fear disorganization of the parenchymatous structure, and inducing disease which ultimately calls for the extirpation of the testicle; whereas in the other form, from the wasting of the organ, the patient is relieved from present suffering, and need apprehend no further trouble.

Although the spermatic artery, the direct source from which the testicle derives its supply of blood, is obliterated, nevertheless from its numerous anastomoses with branches derived from the perineal, pudic and inguinal arteries, a supply of blood sufficient for the maintenance of the organ is secured, while the safety and success of the plan I have described entitles it to the consideration of every professional man who aims to contribute his mite to the general store of information, and who wishes not to be led on tacitly by the great masters who within the last few years have shed such brilliant light upon the surgical world.Northern Lancet.

\title{
POISONING BY THE OIL OF CEDAR.
}

[Communicated for the Boston Medica] and surglen] lournal,]

ON the 21st of July, 18-, I was called to see Miss — who, the messenger said, was suffering from epidemic erysipelas, which prevailed in this region at the time, and my presence was desired as soon as possible. At my arrival $\mathbf{I}$ found she had been already sick two days, and seemed rapidly sinking. Her face was swollen and livid, and the veins of the face, head and neck, were fully distended. Her eyes were somewhat bloodshot, and the pupils dilated; but as the patient had been weeping, I did not know but the sclerotic congestion might in part have been caused by that.

One half of the lower lip, and part of the chin, and down upon the 
side of the neck, were much swollen, and of a dark hue almost like ecchymoses from a bruise. The tongue and gums, too, were involved in a similar swelling and lividity, and the fauces in spots were denuded of their mucous covering. The patient seemed much exhausted, or in a state of prostration; and although she made quite an effort to inspire, when the air passed out of the chest all strength seemed wanting, and the expiration was slow, and without assistance from the expiratory muscles-the chest appeared to fall together from its own weight. The pulse was fluttering, feeble and slow, not more than fifty-five in a minute, and very irregular. The hands at times were clenched, and the jaws firmly fixed; but the patient said this was caused by the intensity of the pain in the abdomen, where the erysipelas had become seated-and so said her friends.

On examining the abdomen, I found it swollen and hot, but with no appearance of erysipelas externally, and there was considerable distension and tenderness at the pit of the stomach. The skin was dry and parched. The bowels had been quite loose the first day, but for the last twenty-four hours nothing had passed them.

Such were the symptoms; but 1 could not read from them that she was suffering from erysipelas: to me they plainly indicated another source for all these difficulties. The family were all very respectable, and the character of the girl unimpeached. Yet I could not avoid thinking of the Purisian physician, who was politely invited by his friend in the city, on his arrival in America, to visit a patient suffering from a strange and obscure disease. After proper investigation, the learned Frenchman pronounced her cnceinte. The attendant said that could not be, for she was not married! "Elle est enceinte"! replied the visiter. "But," said the family physician, "I tell you that is not possible, for she is not married, and, besides, she is a member of the church"! "I do not know vat be dat disease you call de membre of de shursh," replied the inperturbable citizen of the gay metropolis, "but dis ting I do know, she be enceinte, and vill be ver vell per la encouchement."

I requested a private interview with the patient, during which she acknowledged to me that she had taken over half an ounce phial full of what she called the oil of savin-probably, however, it was the oil of the Juniperus Virginiana, as I had known this to be sold by a vender of nostrums in this vicinity, as a safe and sure means of inducing abortion. As the phial and the remaining contents were burned up, I had no means of deciding positively which it was, but do not think a patient likely to recover after swallowing that amount of the oil of the Juniperus Sabina.

Under the use of Dover's powders, mild laxatives, demulcent drinks, and external fomentations, in a few days the patient was in the enjoyment of comfortable health, but she never was very well for two or three months from the above sickness, when she left town, and I had no further knowledge of her.

From information derived from her, and from others since then, I am of the opinion the oil is not unfrequently taken for the same purpose she 
had in view; and have no doubt proper measures would fasten the guilt upon those who incite to the horrid crime of murder from the miserable hope of making a little money from the sale of the poison.*
Waterbury, Vt., May 15, 1851.
C. H. Cleaveland.

\section{TIIE PAST AND PRESEN'T S'TATE OF THE MEDICAL PROFESSION- HOMCOPATHY.}

[Communicated for the Boston Medical and Burglcal Journal.]

AT no period have the means for the acquirement or diffusion of medical knowledge been more various and multiplied, than the present-by the increased number of medical schools, the lectures of learned professors, the formation of medical societies, the writings of able authors, the abundance of periodical publications, and the thousand facilities afforded by new discoveries and inventions; and yet, strange to say, the esteem and respect, in which the medical profession is held by the better informed members of society and the public at large, was never at a lower ebb than at this time.

This is an anomaly, for which it would be difficult to find a parallel - unless we may be allowed, without profanation, to compare it with theology - which, equally at fault, has incurred the like penalty. Both pathology and theology profess to be taught and guided-the one by the book of nature, the other by the book of God-whence most of that which is practical and useful is readily acquired by the diligent observer. But both, in their turn, present a mystery " which passeth understanding," for the solution of which they are in cluty bound to abide the time when it shall please their Maker to give them a new set of organs, or a higher grade of intellect. But instead of this, with the impatience of their prinitive ancestor they must climb the forbidden tree of knowledge, where, soon lost among its numerous branches, or bewildered by their giddy beight, they are prone to descend, to ascertain how far their airy visions comport with the accredited truths and established facts, upon which they had fondly built, and find them irreconcileable -whence confusion of tongues, discordant opinions, multiplication of sects, and that unanswerable question, Who shall decide when doctors disagree? - which, become proverbial, has made more skeptics, in physic as well as religion, than all other causes combined.

But dropping the parallel, and leaving theology in abler hands, it may be truly said that medicine has obstacles to encounter, peculiar to itself. Not only has reason, thus misapplied, proved an ignis fatuus to mislead, but that experience itself, upon which we had supposed we might safely rely, from the perplexities of the case too often proves fallacious. In the treatment of diseases, we do not duly consider that many of them are self-limited in their nature, or controlled by the innate conservative powers of the constitution-that cures may often be ascribed to the inoperative, and perhaps injurious remedies we have employed, rather than.

* For other cases of poisoning by cedar oil, reported by Dr. S. C. Wait, of the State of New York, see this Journal for July f8, 1849.-Ev. 